\title{
Jayme Mathias - Outrora: crônicas de uns dias perdidos
}

Rio de Janeiro: Multifoco, 2016

Leonardo Lima Ribeiro ${ }^{1}$

São patentes algumas premissas basilares que testemunham o processo de composição do livro Outrora: crônicas de uns dias perdidos (2016), de Jayme Mathias. Ao mesmo tempo, também é perceptível a presença de outras premissas, embora destinadas precisamente aos leitores que se permitem atravessar pelo texto. $\mathrm{O}$ corpo de indicações que perfazem a totalidade dessas premissas identificadas segue decerto em Outrora como uma espécie de petição majoritária: um aviso aos navegantes do intempestivo, alerta que deve ser objeto de reflexão e intuição tanto para os leitores do escrito quanto, curiosamente, para o próprio autor da obra.

As premissas mencionadas seguem adiante, bem como as razões imanentes ao exórdio do escrito, de acordo com as quais Outrora permitese assentar enquanto adequado objeto de experiência vital vertida no mundo contemporâneo. De fato, como observaremos a seguir, trata-se de uma estrutura viva que solicita, para melhor aproveitamento intuitivo de sua espessura, algumas petições basilares, nas quais podemos identificar ressonâncias modernistas, por meio de que testemunhamos na surdina um legado presente que projeta retrospectivamente Outrora à época do espectro histórico de literatos e obras antes já plasmadas.

Enunciando-se como "um homem que desistiu de falar e tomou a decisão de escrever" após ser acometido pelo incidente "de ser tomado pela multidão", Marcel Padilha, o protagonista de Outrora: crônicas de uns dias perdidos justifica tal gesto para si tanto em função da angústia sentida pela vertigem da incomunicabilidade entre os seres humanos entendidos como corpo social que nega em si e para si o diálogo - quanto pela alegre descoberta de formas e conteúdos mais complexos de comunicação; comunicação antevista enquanto motor da escrita, alegre descoberta que se põe em referência às instâncias inumanas da vida, como os entes caninos (Mathias, 2016, p. 62).

É justamente no limite do expresso que Marcel Padilha tácita e paulatinamente passa a sentir-se possuído, dominado pelo destino

\footnotetext{
${ }^{1}$ Mestre em filosofia pela Universidade Estadual do Ceará (Uece), Fortaleza, CE, Brasil. E-mail: leoribeiro22@gmail.com
} 
processual da escrita criativa como prática de vida. Portanto, em Outrora, o espectro da criação literária e da imaginação criadora nele implicado iniciam, persecutoriamente, a tutela sobre Marcel e o escritor da obra, assaltados pelo mais profundo dos silêncios e desconfortos abdominais ("estômago e dor, Clara, meu amor") - embora, ou justamente por isso, destinado à empresa da literatura e pinturas de obra como missão de vida, de forma assemelhada a um Paterson, personagem poético recentemente anunciado pelo diretor Jim Jarmush, sob a forma audiovisual (Paterson, 2016).

Ao mesmo tempo, não nos enganemos: Outrora: crônicas de uns dias perdidos, sob auspícios de Marcel Leônidas Padilha (discípuloprotagonista) e Assis de Sá Carneiro (mestre), dois pseudônimos, é precisamente o movimento de uma estória que se exprime pelo mote da incompreensibilidade como virtude literária atribuída ao próprio autor (Jayme Mathias), incompreensibilidade sublimada quando este torna-se consciente, por meio de Marcel, de que é seu o atributo de ser acometido pela contingência do ato de escrever "em fluxo desconexo" - tarefa adquirida de um mestre (Assis de Sá: quem sabe, um Schopenhauer educador?).

É tomando isso como premissa que, por sua vez, o leitor é orientado para o espaço estrutural da escrita, a ser, no limite sentido, vivido enquanto topologia da despossessão de si. Aqui, o espaço da escrita torna-se composto por poemas, diálogos filosóficos, prosas e pinturas, que procedem operando a função de um gatilho magnético a partir do que se induz o leitor para os descaminhos das múltiplas aberturas para alteridade, compreendida, ressalte-se, como um outro complexo a ser forjado infinitamente a partir do ritmo da leitura de distintos leitores, porquanto, para o autor, a alteridade e a multiplicidade de seus sentidos intrínsecos não são uma natureza dada de antemão, mas algo peculiar, uma tarefa inerente ao ato de ler uma obra. Ler, assim, transmuta-se em condição de experiência sensível por meio da qual o leitor potencializa Outrora, conduzindo-a para direções antes inesperadas pelo próprio escritor do tecido literário evidenciado.

A isso devemos chamar de alteridade em rede infinita de superação de si, mesmo que para propagar a possibilidade da conquista de um colapso porvir, o que torna o livro algo inacabado, isto é, espaço aberto para sua autossuperação como gesto de entrega e doação aos leitores que a ele se assomam. Se esse for o caso, então faz sentido analisarmos a obra sob o 
prisma de um gatilho magnético a partir do que se induz a múltiplas aberturas para alteridade por parte do leitor e seus outros linguísticos ficcionalizados, tal é o presente que o autor tem precipuamente a nos oferecer combativamente, contra o niilismo comercial escandaloso e petrificante que nos torna passíveis de capitulação por meio dos escudos mais vorazes da miséria do cotidiano.

Realmente, signos anteriormente apontados de passagem ainda podem ser aqui mais bem observados, como o indicativo da questão da possessão pelo impulso da aceleração do movimento da escrita, algo que acomete o escritor num gesto frenético. Pura necessidade ontológica. Trata-se de uma espécie de transe, cuja expressão é imanente ao infinito movimento de composição da escrita, que só ganha em dinâmica ao passo da presença crônica de um mal-estar, vertido como turbilhão abismal no estômago que, consequentemente, produz reativamente um ódio contra a boca por meio do que socialmente se come. A dor no estômago enxaquecoso, que provoca ódio relativamente à própria boca, inscreve o vivente na deliberação pelo calar-se seja alimentícia seja comunicativamente, cravando e cerrando os lábios contra eles mesmos, num extenuante autoboicote (Mathias, 2016, p. 60).

Primeiramente, trata-se de diatribe feita ao estômago e seus aspectos digestivos. Em seguida, parte-se de uma indisponibilidade antiboca e antiestômago, nos marcos da insociabilidade ou silêncio comunicativo e alimentar, tornando-se então precípua a exigência de uma escritavendeta, distribuída em velocidade cortante, tal qual um esgrimista baudelairiano, ${ }^{2}$ que aprende a resgatar para si as energias a partir de outras fontes retroalimentáveis. Por conseguinte, jaz aqui então justamente uma das novidades presentes no livro, imanentes aos processos corporais muito peculiares, e pelos quais a escrita de Outrora espraia-se com máxima potência. Por conseguinte, como podemos intuir pelas próprias letras de Jayme Mathias (autor em pano de fundo dos pseudônimos), a velocidade da escrita como gesto é de fato uma necessidade que lhe acomete (Mathias, 2016, p. 70).

De fato, o arremate vem acompanhado de algumas entrelinhas. Uma delas é a da articulação das pessoas não pela mediação da razão e seus

\footnotetext{
2 Charles Baudelaire (1821-1867) realmente se via como espécie de esgrimista durante a composição de um texto. Esgrimir por meio da escrita é a prova do combate, um meio pelo qual poderia estabelecer suas pequenas prosas poéticas [o spleen de Paris] (1869) e as aclamadamente, à época, malditas Flores do Mal (1857).
} 
arroubos de frieza natimorta, mas pela identificação sentimental estabelecida pelos impulsos de dores vividas seja coletivamente, seja no âmbito das microrrelações. Do mesmo modo - o que é uma expansão da identificação sentimental retratada nos movimentos da escrita -, torna-se patente a presença de uma objetividade caótica vertida como conteúdo fundamental do pensamento, impregnado de metáforas que fazem do exercício do pensar uma prática linguística implicada no acolhimento de energia erótica. Retratada no livro, tal energia é descrita como o que força o pensamento e a imaginação na direção da fusão canibalesca e orgiástica dos corpos em vida (Mathias, 2016, p. 19). Ora, o expresso enuncia que o autor da obra está muito bem acompanhado, uma vez que não está muito distante de filósofos - afora Spinoza, Nietzsche e Deleuze - do calibre de Georges Bataille, em sua obra O erotismo (1957).

Numa primeira visada, Outrora não nos autoriza a dar referências literárias externas passadas como mediação na relação leitor/livro (Mathias, 2016, p. 131). Não poderia ser de outro modo que, para Mathias, os "velhos reptilianos" aparentemente inteligentes e sob o peso dos arroubos da história estão amiúde "embotando o novo", porquanto se põem inexoravelmente a diminuir tudo o que apareça como novidade, que passa a ser transposta ao conjunto das "memórias vazias e sem rumo" de estéril passado natimorto (Mathias, 2016, p. 131). De qualquer forma, para que a obra seja tanto verdadeiramente sentida quanto reflexivamente pensada, e não apenas cegamente absorvida ou mastigada ao ser exclusivamente intuída enquanto parâmetro autoreferenciado ensimesmado, é que se faz necessário desobedecer a prescrição contra os idosos, camaleões ou repteis sedentos de gozos, conquanto, segundo Mathias, enormemente fatigados e embotados pelo peso das histórias das opiniões que arrastam nos ombros. Para tanto, é aqui imperativa a admissão de que a injunção dos espectros ancestrais da humana história artística viva acomete, consciente ou inconscientemente e para o bem ou para o mal, criações literárias contemporâneas quando os pássaros solilóquios não esperam, às escuras dos escombros do mundo.

Um livro passível de experiências vivas de leitura e hermenêutica também deve estar à altura da tarefa de se permitir abrir brechas para admissão do estabelecimento de uma pesada visão idosa, retrospectiva judicativa, que implica os contornos vivos do passado envelhecido. Evidentemente, não para deixar assassinar-se ou apequenar-se enquanto novidade expressa, mas para permitir-se avaliar a própria qualidade da 
sua novidade de outro ângulo analítico que não o do próprio autor sob legado nietzschiano, ou seja, com critério que não parta apenas da pressuposição evasiva de pulsões ou forças avulsas eternamente retornáveis, num móbil ontológico autoremissivo negador voraz dos acontecimentos da história e seus desdobramentos culturais. Afinal, nem tudo o que é julgado como efeito dos acontecimentos da história deve ser assertivamente taxado como deletério ou farsesco, mesmo da perspectiva vitalista de Fernando Pessoa (1888-1935) ou F. W. Nietzsche (1844-1900) o qual encontra sua própria maneira de fazer história com as sintomatologias das epistemologias morais de sua época, tangenciando o registro de uma dialética hegeliana, por Nietzsche muito criticada, embora por ele mal compreendida. ${ }^{3}$ É preciso, por outro lado, permitir-se à avaliação de que, voltada às ruínas das culturas pretéritas, conquanto assentada no tempo cotidiano e amparada na forma de obra literária hodierna, pressiona criticamente o presente e seus efeitos, rachando-os ou fendendo-os no itinerário de caminhos porvir realmente não atávicos e antes não planejados. É decerto nesse sentido que, adiante, reinscreve-se a obra de Mathias na dinâmica viva dos espectros da história literária, não para fixá-la na impotência do passado referenciado, mas para melhor elaborar o diagnóstico de sua verdadeira novidade pelo critério da crítica aos possíveis anacronismos inconscientes (e não conscientes) do autor.

São justamente esses espectros ruidosos ou ruínas latentes do passado que gostaria de, adiante, ressaltar na tensão com Outrora; fantasmas de escritores que, na diferença, repetiram e repetem sentimentos fraternos aos de Outrora. Referências a Georges Bataille (1897-1962) e a seu erotismo clínico (os quais não estão diretamente citados no texto), por exemplo, serão usadas aqui para refletir acerca dos movimentos descritos a partir dos personagens de Marcel e Clara. Existem inúmeras semelhanças entre as pretensões orgásticas de Clara (na sua relação com Marcel) e as sessões do erotismo de Bataille, por exemplo. Os diálogos de Clara com Marcel são uma ode ao erotismo batailliano. Nesse sentido, plasmam-se no escrito agulhas sádicas que perfuram a totalidade do corpo; fusão de fluxos residuais da pele; rosas e espinhos que penetram a carne viva como testemunho de uma vontade de beleza. Há impulso lúdico em Outrora, no sentido de um erotismo batailliano ensaiado, que entrecruza como

3 Trata-se mais precisamente aqui da II consideração intempestiva: sobre a utilidade $e$ os inconvenientes da história para a vida (1874), de F. W. Nietzsche. Publicada, no Brasil, em conjunto com ou textos claramente anti-hegelianos, sob o título Escritos sobre a educação (2005). 
instrumentos inconscientes - para urdidura da beleza viva que toma a morte iminente como palco estético - Rabelais (1494-1553), Sade (17401814), Sacher-Masoch (1836-1895), Freud (1856-1939) e Nietzsche. De algum modo, essa urdidura de Bataille em subsolo é pano de fundo dos circuitos afetivos que interseccionam os personagens Clara e Marcel (Mathias, 2016, p. 65). Clara é personagem que desempenha papel tão importante quanto Assis de Sá para autoeducação de Marcel; procedendo também como espécie de mestre/amante, embora arraste Marcel por caminhos que não o do preceptor (Assis de Sá), vias contornadas e atravessadas pelo gozo das penetrações bataillianas como dispêndio amoroso (Mathias, 2016, p. 63). As prosas que tomam como objeto Clara e Marcel são as mais belas de Outrora, porque transpõem Marcel do âmbito da sabedoria filosófica advinda do mestre Assis de Sá para o vazio intransponível das forças telúricas femininas, correlatas, metaforicamente, a um mundo em essência atravessado pelas metamorfoses das carnes que se violam. É nesse ponto preciso que se torna ainda palpável o legado antropofágico batailliano em Outrora.

Trazendo essa perspectiva para refletir sobre o livro, poderíamos inferir que Clara, em relação a Marcel, diferentemente de Assis de Sá, é personagem cuja tipologia não apenas remete ao telúrico erotismo batailliano, podendo mesmo advir como um personagem de Henry Miller (1891-1980), D. H. Lawrence (1885-1930), W. Burroughs (1914-1997) ou Thomas Mann (1855-1955) no registro de trocadilhos grotescos pantagruélicos inerentes ao romantismo modernista imanente às figuras femininas. Clara, assim, volta-se para Marcel, e Marcel funde-se com Clara em pactos demoníacos, como forma de equilibrar corpo e espírito, sentimento (Clara) e razão filosófica (Assis de Sá). Ademais, tal alteridade sobre a qual antes já havíamos tratado tem justamente como atributo algo da energia canibal (Marcel/Clara) agora expressa, num misto claro que tenciona linguagem e afetos transversais (intersubjetivos e incorpóreos) que emanam tanto do exercício da escrita quanto da percepção daquele que pelas letras é tocado. Ainda no tocante a esse ponto, as letras de Jayme Mathias são capazes de apresentar uma troca selvagem de afetos de amor entre personagens/imagens cuja presença é mediada por grunhidos e desesperos, escuridão e luz de velas. Um presente para o espectador, disposto na expectativa de seus próprios descalabros.

Esse nível de leitura deve ser amiúde considerado enquanto suprema alegria, cujos recônditos anunciam os frêmitos da mais potente liberdade. 
Liberdade que, enfim, pode conduzir paradoxalmente para horizontes tenebrosos, os quais mergulham o leitor na possibilidade de pensar que o amor não é uma experiência de conservação da vida, mas, pelo contrário, é intuição de que a verdadeira paixão só é sentida quando nos dispomos ao nível da intensidade dos casamentos que, em vida, despossuem e arrastam para abismo da morte entendida como estética da transformação de si. Como arrematava e fazia arrebatar Arthur Schopenhauer (1998, p. 71), uma metafísica da morte e suas pulsões é "retorno ao ventre da natureza" que se ama. ${ }^{4}$ Com Outrora de Jayme Mathias, atesta-se, ao fim e ao cabo, que não foram apenas os [pré]românticos alemães sob auspícios de Shakespeare (1564-1616) Herder, Hamann, Hölderlin, Schiller, Goethe etc. - que tiveram a ousadia de fazer do sexo o móbil em direção aos ventres da morte conquistada, a ser usufruída com amor num gesto de entrega à verdadeira vida.

\section{Referências}

BATAILLE, Georges (1957). L'Érotisme. Paris: Minuit.

MATHIAS, Jayme (2016). Outrora: crônicas de uns dias perdidos. Rio de Janeiro: Multifoco.

NIETZSCHE, Friedrich W. (2005). Escritos sobre a educação. Tradução de Noéli Correia de Melo Sobrinho. São Paulo: Loyola.

O AMOR é mais frio que a morte. Direção: Rainer Werner Fassbinder. Alemanha Ocidental, 1969. Título original: Liebe ist kälter als der Tod.

PATERSON (2016). Direção e roteiro: Jim Jarmush. München: K5 International. SCHOPENHAUER, Arthur (1998). Metafísica do amor, metafisica da morte. São Paulo: Martins Fontes.

Recebido em 14 de maio de 2016.

Aprovado em 3 de junho de 2016.

${ }^{4} \mathrm{E}$, se esse for o caso, o amor pode ser mais frio do que a morte, como diria R. W. Fassbinder (O amor..., 1969). 